\title{
From the Editor of Sexuality and Disability: Are We Still Interested? Are We Still Invested?
}

\section{Sigmund Hough ${ }^{1}$}

Published online: 5 August 2019

(c) Springer Science+Business Media, LLC, part of Springer Nature 2019

The journal of Sexuality and Disability continues to be a professional home and foundation for many, and a place of professional rejuvenation and exploration for many more. If you are new to the journal, we give to you a "BIG WELCOME" and invite you to participate as a reader, author, academician, clinician, educator, service provider, researcher, advocate, or person seeking information. Over decades of contribution to the literature on sexuality and disability healthcare, we have been a part of the growth, understanding and advocacy. Most important, we continue to be a part of the change in how we look and examine the topic, the needs, and the response in terms of best practice-evidence based approaches. With the intelligence, experience, motivation and supportive dedication from our authors, readership, peer reviewers and editorial board, and resources with guidance from the Springer Staff; our journal's mission continues to be strong and meaningful. This international effort continues as a strength in the field of sexuality and disability. The dynamic flow and complex layers of knowledge from a global perspective allows us to add an open window of opportunity to learn not just what we are taught, but to also learn what we do not know. Are we still interested? Are we still invested? The answer is "Yes." Since 1978, Sexuality and Disability continues to refine our knowledge to have impact on education, research and practice. Sexuality and Disability makes available original impact articles addressing the mental health and medical healthcare aspects of sexuality in relation to rehabilitation, hospital, academic and community settings, publishing up-to-date articles, case studies, clinical practice reports, reviews, featured articles, historical articles, special grand rounds topics, brief research reports and survey data reports. Value benefit is provided to authors through worldwide electronic exposure and professional access, while readership gains from scholarly contributions to advance the field through research, evidence-based, bestpractice and educational articles. Individual contributions from the local and international community delivers a wealth of information with broad perspective on the topic of sexuality and disability.

Thank you for joining our professional efforts.

Sigmund Hough

Sigmund_Hough@hms.harvard.edu

Beverly, MA, USA 
Publisher's Note Springer Nature remains neutral with regard to jurisdictional claims in published maps and institutional affiliations. 